ORGANIZATIONAL TIME: A DIALECTICAL VIEW ${ }^{1}$

\author{
MIGUEL PINA E CUNHA \\ Departamento de Gestão \\ Faculdade de Economia \\ Universidade Nova de Lisboa \\ Rua Marquês de Fronteira, 20 \\ 1099-038 Lisboa - Portugal \\ E-mail: mpc@fe.unl.pt
}

\footnotetext{
${ }^{1}$ I want to thank João Vieira da Cunha for his significant contribution for the ideas on this paper. The suppport of Instituto Nova Forum is gratefully acknowledged.
} 


\title{
ORGANIZATIONAL TIME: A DIALECTICAL VIEW
}

\begin{abstract}
We present twelve propositions constituting a contribution to a contingency view of time in organizations and synthesize apparently opposite perspectives of time. To articulate them, we relate the 'planning', 'action' and 'improvisation' strategic orientations to the 'dependent', 'independent' and 'interdependent' perspectives of the environment. Then, we relate these strategic orientations related to approaches to the problems of scheduling, synchronization and time allocation. 'Action' strategies rely on event time to handle scheduling, use entrainment to synchronize with their environment and view time as linear. 'Planning' strategies use even time to handle scheduling, impose their internal pacing upon the environment and view time as cyclic. 'Improvisation' strategies use 'even-event' time to handle scheduling, synchronize via 'internakexternal' pacing and hold a spiral view of time. Our argument strengthens the case for a more deliberate approach to time in organizations and favors a dialectical view of organizational phenomena.
\end{abstract}

Keywords: action, contingency, dialectics, improvisation, planning, synthesis, time. 
It is hard to find many explicit debates in the organizational literature on time. However, this tranquility is only apparent. If we look at the ongoing debates in the strategy literature, we can relate some of the most important of them to time-related issues. The debate between the so-called 'design' and 'learning' schools (Ansoff, 1991; 1994; Mintzberg, 1990, 1991, 1994) echoes the difference between cyclic and linear perspectives of time. The 'design' school, which contends that the best performing organizations are those that plan their future, often assumes that the past is a good guide to the future, an assertion shared by those who see time as a cyclic phenomenon where the past is often a template for the future. The learning school, which contends that the best performing organizations are those that act out their future, often asserts that relying on the past is a threat to the future, mimicking, in a way, the unimportance of the past shared by those who see time as a linear phenomenon, never threading the same path twice.

Time has also been used explicitly to address other debates in the field of organization studies. One of the most recent of such attempts was Brown and Eisenhardt's (1997) use of the concept of 'even time' to strengthen the case in favor of incremental strategies. These authors demonstrated that successful new product development processes were those that were time-paced and not those that were eventpaced. This means that instead of relying on discrete external events (event time), such as a new product launch by a competitor, companies should act according to the hythm it set for itself (even time), launching a new product every six months, for example.

Finally, time was also used to highlight previously less visible practices. Ancona 
and Chong's (1996) concept of entrainment draws on biology to show how organizations often adapt to some relevant timings in their environment. In this manner, they used time to provide an alternative to the long-standing assumption that firms were mostly responsible for what happens in an industry. Regular cycles such as the fiscal year and irregular ones such as technologies' life spans, can greatly shape the action of industry incumbents.

Taken as a whole, these three instances reflect the realized and potential contribution that research on time has in store for those concerned with the strategy process. However, research on strategy may also hold a potential contribution to research on time. We contend that this potential can be detected in recent attempts to integrate the opposing arguments that constitute the more visible debates in modern strategic thinking. If the 'design' and 'learning' schools can be integrated (Brews \& Hunt, 1999), if there is a possible synthesis between incremental and punctuated strategies (Orlikowski, 1996) and if external demands can be integrated with internal wills (as research on improvisation shows [see Hutchins, 1991; Johnson \& Rice, 1984; Weick, 1999]), then a synthesis between linear and cyclic time, even and event time, and between internal and external pacing, may be possible. To make this point, we draw on the literatures on strategy and time to illustrate how the three major time-related issues in organizations scheduling, synchronization and allocation - may be addressed by a synthesis in each of these three pairs of apparently opposite views of time. To accomplish this, we start by relating different strategic orientations to different perspectives of the environment, in order to contribute to the foundation of a contingency approach to time-based organizational issues. We posit that when organizations have a dependent approach to 
their environment, they are likely to favor action over reflection. Conversely, if they have an independent approach to their environment, they will probably favor reflection and planning over action. Finally, if they have an interdependent relationship with their environment, they will mostly rely on a synthesis between planning and action.

We continue by relating an organization's dominant orientation towards strategy (acting, planning or both) to its approach to the problems of scheduling, synchronization and time allocation. Organizations that favor action over reflection tend to rely on event time to handle scheduling issues, to use entrainment to synchronize with their environment and mostly hold a linear view of time. Organizations that privilege reflection tend to rely on even time to handle scheduling issues, to impose their internal pacing upon the environment and to hold a cyclic view of time. Organizations that attempt to find a synthesis between planning and action tend to solve scheduling issues via 'even event' time, synchronize via 'internal and external' pacing, and hold a spiral (cyclic and linear) view of time. For the purpose of this discussion, we rely on a definition of time as "a symbol for a triadic relationship between two or more continua and a third dimension of consciousness which connects the two continua" (Kavanagh \& Araujo, 1995: 109), because it is ample enough to contain the perspectives on time we are discussing.

The major contribution of this article is to expand the few attempts to strike syntheses between two apparently opposite views of time (e.g. Burrell, 1992) in order to encompass the three time-related issues organizations face. Additionally, by using the dominant strategic orientation to provide a link between the approach to the environment and the choices regarding time-based decisions, we aim to contribute towards a 
contingency view of this phenomenon. Finally, this research strengthens the argument that most apparently opposite phenomena in organization studies may be integrated through syntheses.

To this aim, we start by relating the organization's relationship with its environment and its dominant strategic orientation. We continue by relating the dominant strategic orientation with the organizational solution to scheduling, synchronization and time allocation issues. We finish by discussing the main contributions and shortcomings of our argument and by providing directions for practice and research.

\section{TIME, ENVIRONMENT AND STRATEGY}

The relationship between a firm's approach to its environment and its strategic options has been extensively researched (e.g. Lawrence \& Lorsch, 1967; Dill, 1962; Aldrich, 1979). The relationship between a firm's strategic options and its options regarding timerelated issues, has often been addressed only implicitly, but has quickly moved to the foreground of researcher's concerns (e.g. Brown \& Eisenhardt, 1997; Moorman \& Miner, 1998a, 1998b). Thus, a possible way of looking at the relationship between the organization's options in time-related issues and its approach to its environment is by using its strategic options as a link between these two aspects. In order to do so, we divide the possible approaches an organization can have towards its environments into three groups, using to Roberts' (1994) typology: the dependent orientation, the independent orientation and the interdependent orientation (see also Campbell, 1949). Although not derived empirically, and thus losing some robustness, this typology has the merit of articulating an orientation - the interdependent - that is mostly absent from texts 
on strategy and organization (for an exception see Machin \& Carrithers, 1996). Additionally, to encompass the spirit of the major debates in the strategy literature we divide strategic orientations into three categories: an action orientation, a reflection orientation and an improvisational orientation (a synthesis between the two).

The 'dependent' strategic orientation posits the rule of the environment. It claims that the major role of managers is to adapt organizations to their environments. This approach assumes that there is such thing as an independent set of external conditions which can be misperceived or not, and over which the organization has little power to act (Lawrence \& Lorsch, 1967). Porter's (1982) five forces model, which allows a company to analyze its industry and select a position in it, in order to maximize performance, is an example of this approach.

The relevance of this view has allegedly increased with the recent mapping of the new competitive landscapes in most industries (Bettis \& Hitt, 1995), where quick radical changes are commonplace. Under these circumstances, planning makes no sense because the environment changes at a faster pace than that at which the organization can turn out new plans and because the complexity of those changes is such that an organization seldom has the capacity to comprehend them (Mintzberg, 1994; Stacey, 1991). Thus companies can only choose to act as quickly as possible hoping that the few actions that are successful enhance the firm's fit with its environment until new changes emerge. Indeed, this has been the rhetoric underlying most business best-sellers, which call on managers to create "the necessary disorganization for the nanosecond nineties" (Peters, 1992).

This focus on action to the detriment of planning has also been framed as a 
challenge to current strategic processes and, more broadly, current organizations. Authors of this school argue that in fast-paced environments organizations must abandon command-and-control structures composed of specialized roles and should rely instead on nimbler informal, cooperation-based forms such as the network (Powell, 1990) or the clan (Ouchi, 1980). This argument is grounded in the importance that effectiveness has in guaranteeing the organization's survival in ever-changing contexts. Turbulent environments do not hold in the same state long enough for companies to be able to find a favorable competitive position and exploit it until it, as hoped, becomes a 'cash cow' (Emery \& Trist, 1965; Hax \& Majluf, 1983). Thus, the most important skill an organization can possess in this type of context is the ability to jump from one opportunity to the next, accompanying the flow of the market. Firms enjoying such a skill put a premium on flexibility. Their managers' most important roles are those relating to the collection and distribution of information (Mintzberg, 1975). Beyond that their responsibility is limited to allowing employees to take the necessary actions to respond to the current state of the environment (Greenleaf, 1974). This action is coordinated by an informal structure where no control mechanisms, visible (Mintzberg, 1995) or invisible (Ezzamel \& Willmott, 1998), are present to thwart employees' creativity (Amabile, 1998).

The organization also seeks to be attuned with market cycles, attempting to streamline its internal processes in order to be able to quickly cope with changes in demand (Ancona \& Chong, 1996). However, this alignment with market cycles is more concerned with exploration (finding new opportunities and handling new challenges) than with exploitation (benefiting from the present markets and products). Thus, the purpose 
of entrainment with the market is not as much to plan the production of current products more efficiently, as it is to be better prepared to substitute products or take advantage of emergent technologies or shifts in the demand pattern.

Finally, this focus on action also means that the company seldom uses the past, at least deliberately, as a guide to the future. Instead, one of the more important skills that such an organization attempts to cultivate, is that of 'unlearning' (Argyris, 1993) in order to avoid the negative impact that experience has on handling novel challenges and opportunities.

Overall, we state that:

Proposition 1: When an organization has a 'dependent' approach to its environment, it favors action over reflection.

The independent strategic orientation regards the organization as the major driving force of its fate. It claims that the major role of managers is to alter the competitive environment in favor of their organization. Those proposing this view, which contends that there is not such a thing as an objective and independent environment, are mostly concerned with market structure. They relate success with the firm's ability to attain privileged competitive states such as monopoly or concerted oligopoly (e.g. Chandler, 1962). Those advancing this view, which sees the environment as a social construction among industry incumbents, seek to alter the value proposal of the sector in order to get a considerable share of the market for themselves (Hamel \& Prahalad, 1994).

Under this view, the emergence of hypercompetition (D'Aveni, 1995) does not 
necessarily bring increased pressures for speedier action, because companies are now at the 'giving' end of change. Instead, the new competitive challenges brought about by shortening product life-cycles and the rapid evolution of technology call for more careful planning. It is harder to identify profitable niches, and entering a new market can only be done by stepping out of the dominant frame of reference (Prahalad \& Hamel, 1990). Planning thus becomes a much more difficult, but also a more important, endeavor. The challenge firms face is to be able to analyze the industry and plan action that alters its present conditions in order to get a dominant position in the market and then defend it.

This focus on a more demanding form of planning has been framed as an extension of the challenges facing current strategic processes and, more broadly, current organizations. Authors in this camp argue that in fast-paced environments organizations must implement visible command-and-control structures such as process standardization and direct supervision, which allow for a more thorough implementation of planning (Ansoff, Avner, Brandenburg, Portner \& Radosevich, 1970). The reasoning behind this argument is related to the role that efficiency plays in assuring the organization's success in rapidly changing markets. The distinguishing characteristic of turbulent environments is that change comes not only from the environment itself but also from its players (Emery \& Trist, 1965). Thus, those companies that are not busy planning to create change will be left busy struggling with it as best they can. Moreover, customers in these markets have the same price concerns as in other markets. Therefore, firms need to exploit their market positions in order to sell at a price at which the customer can buy (Iansiti, 1995). Organizations that thrive in these contexts are those that are able to exploit the opportunities they create and are, in that way, able to succeed in securing a 
dominant position in the industry so that they can have a say in its direction. In this sense, the roles of managers are essentially related to planning the future and optimizing the present (Mintzberg, 1994). It is their responsibility to set up the necessary formal structure to control and integrate employees' efforts toward the overall goals of the organization (Barnard, 1938).

This type of firm also seeks to mold market cycles according to its internal pacing, in order to adjust demand to the technological constraints of the company's production process. The goal is thus to optimize the use of the production capacity of the company in order to increase efficiency and minimize the waste of resources. Additionally, this type of strategic process views its history as a recurrent pattern where it either repeats, with different products, the 'question mark, star, cow, dog' cycle (Hedley, 1976) or where it periodically has to alter its frame of reference and shift the basis of competition of its current industry in the process (Hamel \& Prahalad, 1994).

Taking all of this into account, we contend that:

Proposition 2: When an organization has an 'independent' approach to its environment, it favors reflection over action.

The 'interdependent' strategic orientation approaches the organization and its environment as two elements of the same system, where hey affect each other. It claims that the major role of managers is to take advantage of the emergent opportunities and challenges resulting from the interaction between the environment and the organization to deliberately carry forward the goals of the organization and to adapt those goals as the 
market changes (Eisenhardt \& Tabrizi, 1995). This perspective is not wedded to any particular view of reality. When the environment is seen as 'objective', the interdependent orientation is concerned with handling the challenges and opportunities in the environment to modify its strategy as it is implemented (Johnson \& Rice, 1987). When the environment is assumed to be a social construction, this orientation is concerned with enacting a favorable environment which it will then treat as a given external factor for its strategy (Weick, 1979). Although no formal model of this approach has been formulated, the well-known case of Honda's entry into the American motorcycle industry can be said to be an illustration of the latter variation of the interdependent orientation (Pascale, 1995).

The increased complexity resulting from the new competitive conditions of most industries has accentuated the need for this orientation inasmuch as complex systems, such as markets and organizations under this new competitive paradigm, only become adaptive and thrive if they hold a minimal set of rules (Stacey, 1996; Weick, 1996). These rules constitute a minimal structure that allows the organization to remain at the edge of chaos', accomplishing its goals because (and not instead) of emergent and unpredictable events.

This focus on action and on planning is a challenge to the traditional approaches to strategy and, more broadly, to traditional organizing. Authors espousing this view contend that in turbulent environments organizations that choose either the heavy control structures imposed by specialization and supervision or those that favor 'lighter', cooperation-based form, maybe jeopardizing their future (Hedberg, Nystrom \& Starbuck, 1976). This argument draws on the importance that both effectiveness and efficiency 
have in a company's sustained success. Organizations that favor efficiency may quickly fall prey to marketing myopia and produce at the lowest cost a product that no one wants any more (Levitt, 1960). Those that favor effectiveness may succumb to the lure of opportunity traps and spread themselves and their resources 'too thin' over a wide range of opportunities. By so doing, they will ultimately fail to exploit any of these adequately, thus producing a number of excellent products that no one is able to afford (Miner, Moorman \& Bassoff, 1997). Because of this, turbulent environments call for organizations to be able to detect and create new opportunities and then select those that are worthy of actual resource allocation, in order to be exploited for the firm's benefit. Companies that are able to integrate effectiveness and efficiency in such a way, are often skilled in planning as action unfolds, i.e. in improvising. When improvising, firms rely on a pre-conceived plan to coordinate their members' efforts and to increase their ability to address new challenges with current resources (Weick, 1993). Their managers' most important roles are those related with the initiation of action and the allocation of resources (Mintzberg, 1975). Apart from that, they often join the team / organization in making sense of its strategy as action unfolds and in using that post-hoc strategy to achieve its goals (Crossan, 1998). This action is coordinated by a minimal structure, where control mechanisms are often limited to goals and deadlines (Orlikowski \& Hofman, 1997).

Market cycles are important to organizations following an interdependent orientation because their occurrence may trigger improvisational activity if these cycles are at odds with the organization's internal pacing. Additionally, by improvising on external cycles to construct its internal ones as action unfolds, the organization is able to 
integrate its own cycles into the environment, eventually modifying the pace of the latter (Eisenhardt \& Brown, 1998).

Finally, this synthesis between planning and action also means that the company has a 'spiral' perception of time, akin to complexity's use of structure. The minimal set of rules composing a complex adaptive system, such as an organization, is enacted again and again, but always producing different outcomes and resulting from different inputs. It is this linear and cyclic progression that allows systems to grow in both complexity and adaptivity, always using the same ('minimal') structure to create futures that are always novel (Burrell, 1992; Weick, 1995).

Overall, we state that:

Proposition 3: When an organization has an 'interdependent' approach to its environment, it favors reflection and action.

\section{SCHEDULING, SYNCHONIZATION, ALLOCATION}

Organizations face three major time-related issues: scheduling, synchronization and allocation (Hassard, 1996). Each of these issues can be handled via two different orientations towards time. Scheduling problems may be solved by relying on an 'event' or 'even' perception of time. Synchronization issues may be addressed through internal or external pacing. Allocation decisions may be approached via a linear or a circular perception of time. In addition, we contend that each of these three pairs of opposite approaches may be integrated into a synthesis that best fits those instances when reflection and action are both favored. 


\section{Scheduling}

Scheduling issues can be approached either from a perception of time as resulting from the occurrence of important events (event time) or from a perception of time as resulting from the passage of standard temporal units (even time).

Turning to event time, one could define it as time whose passage is perceived through the occurrence of "meaningful events, including those that are related to seasonal variations (Bluedorn \& Dernhardt, 1988: 304). An 'event' approach to time is thus more visible in organizations focused on flexibility, where action results from the response to internal or external changes or occurrences (events) in order to sustain the organization's competitive position. This type of management is thus essentially reactive because of its high responsiveness to changes in its environment. In this light, it is not surprising that 'event-time' underlies most of the major concerns shared by practitioners and researchers because of the expanding perception that the new competitive realities (Bettis \& Hitt, 1995) force organizations to constant change and adaptation.

Moreover, event time is a more robust framework for managing organizations in turbulent environments because it constitutes a heterogeneous perception of time, which means that its passage "rel[ies] on events whose occurrence is more like the irregular formation of clouds than the regular mechanism of the clock" (Clark, 1990: 141). Therefore, this perception allows the organization to produce the requisite variety that complex and changing environments often demand (Weick, 1979). In fact, when comparing a group whose members shared a heterogeneous time-reckoning with one whose members shared a homogeneous perception of time, Clark (1985) found that the 
former outperformed the latter because the turbulent environment both faced favored the first group's ability to adequately respond to unexpected events.

Following this line of reasoning, we argue 'event time' is more popular in those organizations that favor action over reflection because of the intrinsic unpredictability of those events that are used to determine the passage of time, under this approach. More formally, we contend that:

Proposition 4: When an organization favors action over reflection, most of its members hold an 'event' perception of time.

Turning now to consider 'even time', we can define it as that time whose passage is perceived through the flow of "equalized, accumulated units [with] non-evaluative acceptance by large geographically dispersed populations, open[ed] to unlimited extension and with no particular concern for the past, present and future" (Bluedorn \& Dernhardt, 1988: 305). Managing on even time is managing with a focus on shaping the competitive environment. As the research of Brown and Eisenhardt (1997) shows, regular transitions and calendar-based deadlines (e.g. launch a new product every two years) led to a higher number of successful and timely innovations than did event-based deadlines (e.g. launch a new product when a new technology is available). Additionally, and to make our point concerning shaping the environment, this research showed that these calendar-based deadlines were often adopted by the whole industry. Thus, the scheduling choices planned by an organization emerged as the scheduling choices of its whole sector (Eisenhardt \& Brown, 1998). 
Even time-based management also builds on the research that shows that deliberate change is most often triggered by temporal shifts and not by actual problems (Tyre, Perlow, Staudenmyre \& Wasson, 1996). These shifts may be intentional (e.g. a mandatory break during a project to allow the team to reflect) or accidental (e.g. a breakdown in an assembly line which gives employees an empty time to purposely reflect on their action). Additionally, Gersick's (1991; Gersick \& Hackman, 1990) studies on group behavior show that the passage of clock time alone is responsible for changes in action patterns. In this light, even time appears to play two different roles in planned change efforts. Firstly, it influences the behavior of those implementing these changes so that planned deadlines are met. Secondly, it is a resource for this type of change because it provides organizational members the time they need to reflect and conceive that change.

However, even time is a less robust tool in turbulent environments than it is in more placid ones. Its nature as a homogeneous time-reckoning system (temporal units are all equal and there are no gaps between them) prevents it from holding the requisite variety that more complex environments often demand from their members.

All of the above characteristics of even time make it more popular in those organizations that favor reflection over action, because of the role that this approach to time plays as a resource for planning. Moreover, the fact that the passage of even time is shared by all the members of the organization, and those of the larger community for that matter, the perception of time can be used as an additional coordination mechanism that integrates the efforts of individuals into organizational goals. Thus we state that: 
Proposition 5: When an organization favors reflection over action, most of its members hold an 'even' perception of time.

From the argument above, a synthesis between 'even' and 'event' time seems difficult to accomplish. Nonetheless, we argue that an even-event approach to the issue of scheduling is possible. We define even-event time-based management as one focused on manipulative flexibility, which we perceive as responding to changes in the environment - being flexible - in order to shape that same environment. This argument is based on a closer look at descriptions of industry revolutions that shows that these are less often the result of acts of creative genius than that of a mixture of serendipity / good fortune and hard work. Canon's creation of the personal copier is one example (Prahald \& Hamel, 1990). This amounts to a view of change and adaptation as incrementally-punctuated phenomena, where local adaptations often result in long-term discontinuities, a mode of change characteristic of organizations that simultaneously favor action and reflection. In fact, Brown's and Eisenhardt's (1997) research on this type of organization in fastpacing industries, shows that many changes in these firms' strategy and organization occur in a process likened to the gradual heating of water (incremental change) that eventually evaporates (punctuated change). Additionally, Johnson and Rice's (1984) and Orlikowski's (1996) research into computer-mediated work and its implementation, shows that discontinuous changes in organizational processes and practices often arise because of a stream of improvisations (planning while acting) in this technology's implementation process.

In practice, even-event management can be materialized in two ways. The first one 
is through use of even-time management to respond to unanticipated events. As argued by Eisenhardt $(1989$, 1997), the 'real-time' feature of planning in action may be, in organizational settings, somewhat overstated because of the relative inertia of markets and organizations. Thus, a 'real-time' improvisational response in this type of setting often allows enough room for interim calendar-based deadlines (even time) to be put in place in order to enact the necessary flexibility for a speedy and timely reaction (event time). The second way in which a synthesis between even and event time may be reached is through the use of improvisation to respond to the unexpected events that may arise in order to ensure that a calendar-based deadline is met. In fact, research on new product development has shown that execution rarely follows the path traced by planning and that, as a result, deadlines are seldom met without some sacrifices as far as product quality is concerned (Cooper, 1979). Nonetheless, meeting a deadline may be one of the most important features of a new product launch, especially as far as profitability goes (Craig \& Hart, 1992; Deschamps \& Nayak, 1995). However, recent studies on this process espousing an improvisational view, where action and reflection converge (Miner, Moorman \& Bassoff, 1996; Moorman \& Miner, 1998b), have shown that this practice can be used effectively to ensure that unforseen events are handled (event time management) in order for deadlines to be met (even time management), and profitability assured.

The practice of organizational improvisation in either of these two ways, as a way to reach a synthesis between even and event time-based management, also ensures that organizations attain the highest level of resilience from a temporal standpoint. In truth, the two alternatives for integration between these two approaches to time allows the 
presence of "a repertoire of chronological codes which blends homogeneous chronological codes [...] with heterogeneous chronological codes [...which is] essential to long-term survival, especially to efficient innovation" (Clark, 1990: 137).

The features of this synthesis between even and event time make it more popular in those organizations that favor reflection and action, because of the role that this approach to time may play in allowing plans to be created as action unfolds. Moreover, this view of time allows the organization to settle for a compatible (instead of common) timereckoning system that fosters flexibility without jeopardizing coordination. This allows us to argue that:

Proposition 6: When an organization favors both reflection and action, most of its members hold an 'even-event' perception of time.

\section{Synchronization}

The problem of synchronization is related to the choice of reference to align the rhythms of the elements constituting the organization. These elements may either follow the organization's internal pacing or may follow the dominant rhythms in the environment.

The rhetoric of constant change, turbulent markets and increased competition, has been increasing the legitimization of the solution that supports the synchronization of the elements of the organization to its own internal pacing. In fact, both the academic and the popular business press have been urging organizations to streamline their internal processes in order to maximize their speed to survive in these contexts (e.g. Eisenhardt, 1989; Stalk \& Hout, 1990). The goal is not to set the company's pace by that of the 
environment but, instead, to attempt to outpace the environment in order to enhance the firm's competitive position. Thus, the constraints on the pace of the organization are mainly internal and mostly independent of the environment. This view is grounded on the assumption that an organization can deliberately coordinate the different paces of each of its constituent parts and integrate them into an overall concern for increased speed.

The approach that awards the organization the legitimacy to set its own internal paces in order to thrive in fast-changing markets is therefore more viable in a 'creative' orientation, where the firm assumes that it is able to set its own rhythm. This approach is thus more likely to be espoused by those firms that favor reflection over action, as they attempt to deliberately quicken its functioning (e.g. via reengineering [Hammer, 1990]) in order to be able to shape the industry where they operate. Thus:

Proposition 7: When an organization favors reflection over action, internal rhythms are its major source of synchronization.

Recent research on time-based organizational phenomena has challenged the view that organizations can set their own pace without paying much attention to the inherent rhythms of their environments. The use of the 'entrainment' concept has allowed researchers to uncover chronological interdependencies between organizations and their environments (e.g. Clark, 1978). 'When' was added to the 'what', 'how', 'who' and the 'why' of change. Pacing emerged as a determinant element in organizational change as research by Ancona and Chong (1996) and by Orlikowski (1996) showed that more important than planning to speed up the organization, was acting to attune its pace to that 
of relevant environmental rhythms. In fact, this research showed that administrative innovations that were implemented in a way that action could be taken in order to respect relevant external and internal rhythms, were more successful than those that were not so implemented. Thus the constraints on the pace of the organization are mainly external and set by its environment. This perspective assumes that an organization can use action in order to internally enact the pace of its environment, integrating its internal rhythms in order to be attuned with the pace of several timings of its industry.

This approach is thus more viable in a 'reactive' orientation, where the company looks at its environment for guidance in setting its own rhythm. It is thus more likely to be espoused by those firms that favor action over reflection, as they attempt to internally enact the pace of some of the relevant elements of their environment in order to be able to respond to changes in the industry where they operate. Thus:

Proposition 8: When an organization favors action over reflection, its environment's rhythms are its major source of synchronization.

A synthesis between these two apparently contradicting perspectives is, again, hard to find. However, this is only so if we perceive the internal and external rhythms, and the need for higher speed of action as objective realities. If we see reality and time as socially constructed (Berger \& Luckmann, 1967; Maturana \& Varela, 1980) and these rhythms as enacted phenomena (Weick, 1979, Smircich \& Stubbart, 1985), then an integration between the 'faster is better' and the 'entrainment' approaches seems feasible. In fact, drawing on the definition of time presented above (a symbol for a triadic relationship 
between two or more continua and a third dimension of consciousness which connects the two continua), one could argue that the nature of time depends on the interpretative ability of the connecting consciousness. Thus if one fails to make sense (Weick, 1995) of patterns out of the changes occurring in the relevant environment, the latter will appear chaotic, and entrainment will be close to impossible (Bluedorn \& Denhardt, 1988), which the aforementioned research, performed by Clark (1985) in a large hosiery firm, clearly illustrates. Moreover, although the 'when' of change seems indeed decisive for its outcome (Tyre et al., 1996; Ancona \& Chong, 1996), there are indeed trends pointing to a need for increasing speed of action, such as declining product and technology life cycles, higher rates of innovation introduction, and nimbler competitive action (Bettis \& Hitt, 1995; D'Aveni, 1995). In this light, the integration between the two conceptions of synchronization appears to be not only possible but also desirable. We propose that favoring both action and reflection may contribute toward this end.

Integrating action and reflection allows, on the one hand, to respect the pace of relevant stakeholders and environmental rhythms without disrupting the internal pace of the organization. The underlying process that makes this feasible is conceiving a response in real time (improvising) whenever a difference in pace, cycle and/or rhythm between the organization and its environment would call for a resetting of the former's enacted time structure (Orlikowski \& Yates, 1998). In fact, Brown and Eisenhardt's research shows how companies in the fast-changing computer industry are able to maintain their internal rhythms of product development in a very turbulent market through "multiple product innovation [which] involves improvisation of current projects through limited structures and a real-time communication (...) form[ing] a core capability for creating 
frequent, relentless and endemic change that is associated with the success of firms in high-velocity, competitive settings" (Brown \& Eisenhardt, 1997: 32) .

On the other hand, when relying on a synthesis between reflection and action, organizations can, purposefully or not, shape their own rhythms to those of the environment they face. This results from the formalization that recurrent planning (as action unfolds) is prone to (Moorman \& Miner, 1998b; Cunha, Cunha \& Kamoche, 1999). In truth, since perceptions, sensemaking and social construction of internal and external rhythms and pacing occur mostly at the onset of a project (McGrath \& O'Connor, 1996; Dill, 1962), where most planning is done through action (Greiner, 1972), one can easily see that entrainment is not a process that occurs throughout the life of an organization, but mainly at its onset where the probability of improvisation is higher. In both cases, improvisation seems to allow organizations to achieve high levels of speed either by taking advantage of external rhythms or by shaping these rhythms themselves. In this setting, the role of the manager thus shifts from either speeding up the organization or entraining it to its environment, in order to foster a selective social construction of the relationship between the signifiers of time and its passage (McGrath \& Rochfort, 1983) allowing that, through the convergence of action and reflection, external and internal rhythms are both integrated to the benefit of the organization.

In this light, an 'interdependent' orientation, may be fertile ground for achieving this synthesis between the need to speed up the organization and that of attuning it to relevant external rhythms. This approach is thus more likely to be espoused by those firms that favor both action and reflection, as they attempt to be flexible to external paces without disrupting those in the organization. In sum, we contend that: 
Proposition 9: When an organization favors both action and reflection, its own rhythms are integrated with those of the environment to form its major source of synchronization.

\section{Allocation}

The debate between those advocating that time is a linear phenomenon and those advocating that it is cyclic, is perhaps one of the most discussed topics of time-based organizational research (Das, 1993). The focal point of this debate has been the demonstration that the linear perception of time is dominant in the so-called 'western' countries and that that pervasiveness is responsible for fundamental assumptions about work and life (Katz, 1980). We choose to position our discussion of these two categories of time at a lower level of abstraction, relating it not to social paradigms but to organizational practice. In this arena, this debate mostly concerns the issue of time allocation - each of these competing views of time has important effects for the corporate planning process which essentially maps out the allocation choices to be made by the organization regarding time, money and people (Ansoff et al., 1970).

The stream of research advocating that the environments most companies are and will be facing is significantly different fom the those they have been facing in the past is highly congruent with a linear perception of time. Under this perception, the present and the future have little resemblance with the past, and thus the knowledge of what has passed may be of little help to acting in the present or the future (Hassard, 1996). This view is likely to develop in organizations with an orientation towards action, as these 
tend to see planning as a ritual of little importance and with few results (Mintzberg, 1994). Moreover, these firms also fear that the pervasiveness of the past hampers their ability to correctly perceive and address the challenges the environment poses, and they are thus more interested in unlearning that past than in using it to chart their future (Miller \& Chen, 1994). In this approach, managers are called upon to 'fold the future into the present' (Kavanagh \& Araujo, 1995) by relying on action to handle current issues and by looking back into that action in order to make sense of the direction of their organization. In this vein, a view of time that finds little place for the past is more likely to appear in those organizations that favor action over reflection, because these organizations see the changes in their environments as so pervasive and relevant that they seek constant adaptation. This behavior has in the past one of its most potent enemies because the past may blind the firm to its present - let alone its future - and may bind it to its habitual routines, leaving it powerless in the face of an ever-threatening context (Hannan \& Freeman, 1977; Miller, 1993). Considering this, we propose that:

Proposition 10: When an organization favors action over reflection, it mostly perceives time as a linear phenomenon.

Under a cyclic view of time, the past is seen as a template that molds the present and the future. In this approach, organizations are concerned with using planning for two tasks. The first is to extrapolate the future from the past. The second is to detect which past actions and routines are necessary to handle present and future circumstances. The environment is thus perceived to revolve around a set of stages (e.g. the seasons of the 
year) and the organization is deemed (one is tempted to say doomed) to perform very similar actions as the same stage emerges, cycle after cycle (Clark, 1978). This perspective fits the arguments of those that claim that organizational processes can be planned because every instance of these processes is very similar to past ones. In fact, Cooper (1979) has shown that if organizations stick to a standard procedure when developing new products, these are more likely to be successful than those developed under less structured circumstances. In this light, a cyclic perception of time is more likely to be popular in organizations with an orientation towards planning, as these tend to see this process as a way of successfully handling future and present challenges by drawing on knowledge about the past. Therefore, these companies' managers are mostly busy with 'folding the past into the present' (Kavanagh \& Araujo, 1995) by formulating plans that use routines that worked in the past, to handle the issues the organization is facing in the present. In this vein, a view of time where the past plays an important role is more commonplace in those firms that prefer reflection over action because they see the changes in their environment as a re-enactment of what has happened in the past. Therefore, they attempt to plan courses of action to handle these changes inspired by the ways they handled similar challenges before. This approach sees the past as one of its most important assets as it illuminates current events in a way that helps the organization to decide what to do, because the present is mostly the result of the past emerging again (Cavendish, 1982). In conclusion, we posit that:

Proposition 11: When an organization favors reflection over action, it mostly perceives time as a cyclic phenomenon. 
A few authors have already sketched a synthesis between these two perceptions of time (e.g. Filipcove \& Filipec, 1986; Burrell, 1992). However, as Burrell contends concerning Filipcove's \& Filipec's discussion on 'spiral time' explained by the representation of a snake biting its tail and a body in fetal position, "how one would illuminate a course on the management of change solely with a picture of the body in foetal position or the coiled serpent is not immediately apparent" (Burrell, 1992: 169). Burrell's (1992) own discussion is also not very helpful as far as management implications are concerned because his discussion treats either very macro phenomena (post-modernism and anarchy) or very micro ones (absenteeism and sabotage), making the task of understanding the enactment of these phenomena at the organizational level, a difficult one to tackle. A starting point would be to juxtapose the prior conceptualizations of linear and cyclical time. This would result in the following statement: linear-cyclical time-based management consists of folding the past and the future into the present. Based on this statement, a synthesis between cyclic and linear time would have the present as its main stage, as organizational improvisation (favoring both action and reflection) does (Ciborra, 1999). In fact, the two major underlying elements of improvisation, be it in organizational settings or not, is the existence of an underlying plan (which folds the future into the present) and bricolage, i.e. the reworking of pre-composed material, routines and resources to handle present challenges (which folds the past into the present) (Crossan, 1997; Hatch, 1997; Weick, 1999). Thus, when action converges with reflection, cyclic and linear perspectives of time also seem to converge. In this vein, planning under a 'synthetical' view of time, would mean building 'minimal plans' which instead of 
prescribing courses of action, would give organizational members the minimal structure (Hedberg et al., 1976; Weick, 1995) they need for coordination, while fostering action and flexibility. This is close to Pentland's and Reuter's (1994) concept of an organizational grammar that, like its conversational and linguistic counterpart, defines the set of rules needed for variety to emerge, assuming a role close to that of the strange attractors' in complexity theory that are the structures necessary to foster adaptivity (Stacey, 1996). In this sense, plans would amount to what Gearing (1958) called a structural pose, a set of behaviors and routines which is enacted again and again, providing the structure necessary for an organization to evolve. Accordingly, when privileging both action and reflection, organizations are using past routines in novel ways, revisiting the past while progressing on a path of evolution (Crossan, White, Lane \& Klus, 1996; Hatch, 1999; Moorman \& Miner, 1998a), moving ahead in circles - riding a spiral.

Summing up, this allows us to argue that:

Proposition 12: When an organization favors both reflection and action, it mostly perceives time as a linear and a cyclic phenomenon.

\section{DISCUSSION}

Taken together, these twelve propositions constitute a model that contributes toward a contingency view of time in organizations, providing three contributions to the research on temporal issues in organizations. Firstly, they expand the few attempts to strike syntheses between two apparently opposite views of time in order to encompass the three 
time-related issues organizations face: scheduling, synchronization and allocation. In this vein, we argue that when reflection and action converge, so do event and even time, internal and external pacing, and linear and cyclic time. The convergence between even and event time is achieved by planning as action unfolds in order to handle unforseen events to keep 'even' deadlines and to use this type of deadline to respond to unexpected events. The convergence between external and internal pacing is achieved by planning as action unfolds in order to handle differences in pace between the organization and its environment, without fully 'entraining' one to the other. The convergence between linear and cyclic views of time is then accomplished by seeing past routines as grammars upon which the organization may build when adapting to discontinuous changes.

Secondly, our use of the firm's strategic orientation to provide a link between the approach to the environment and the choices regarding scheduling, synchronization and time allocation decisions, contributes toward a contingency perspective of time in organizations. An 'independent' approach to the environment often appears together with 'event' time-reckoning, where scheduling is determined by occurrences in the organization's context; with internal pacing, where synchronization is based on the organization's choice of rhythm; and with a linear approach to time, where the future is allocated to the present. An independent approach to the environment is more favorable to an 'even' time-reckoning system, where scheduling is determined by calendar-based deadlines; to external pacing, where synchronization is based on the environment's rhythms; and to a linear approach to time, where the past is allocated into the present. An 'interdependent' approach to the environment goes together with an even-event timereckoning, where scheduling is determined by both events in the environment and 
calendar-based deadlines. The organization is externally and internally paced, being synchronized according to its own needs and to the rhythms of the environment. Time is seen as linear and cyclic, with both past and future allocated to the present.

Thirdly, by presenting a possible integration between two approaches to the environment (the interdependent view), two approaches to strategy (favoring both reflection and action), and three pairs of approaches to time (even-event time, internalexternal pacing and linear-cyclic time), we strengthen the case for a dialectical approach to organizations. This approach, already suggested in topics such as change (Orlikowski, 1996); communication (Yates \& Orlikowski, 1999); leadership (Follett, 1940; Thayer, 1988) and strategy (Brews \& Hunt, 1999), argues that most phenomena that are assumed to be opposites are, in fact, two different elements of a single phenomenon. By providing the three sets of syntheses we have present here, we join those who argue that this approach may be extensible to many domains of organizational inquiry and social science in general.

There are three shortcomings in our argument that have to be articulated. The first concerns the order of the relationships presented in the twelve propositions we put forth. It is implicit in the statement of the relationships between strategic inclination and time, that the former precedes the latter. This is debatable because one could argue that it is a linear perception of time that supports an action-based strategy, instead of the opposite, as we suggest. Although there is some merit to this argument, earlier research on time in organizations shows that these can have an important role in molding their members' approach towards time, thus supporting our contention. The second shortcoming is related to the theoretical nature of our argument. Our propositions result from the 
literature and, although this includes several empirical studies, these are nonetheless secondary data that were not collected with the purpose of serving as a basis for our propositions. Further research is thus needed to assess the quality and relevance of our model. Finally, there is no well-known criticism of the dialectical approach in the terms we suggest (by enacting syntheses between apparently opposite phenomena), in the literature on organizations. This fact may have blinded us to the limitations of this approach thus limiting the descriptive power of the propositions we have suggested. Again, further research is needed to assess the importance of this shortcoming.

As far as implications for practice go, the propositions we have presented, first and foremost, join those highlighting the benefits that can be obtained from a more deliberate management of time. Indeed, strategy and time appear to be closely linked. This means that the organization's fit with its environment may be jeopardized if the strategy is fit to tackle the major challenges put forth by its context, but the firm's view of time-based decision fails to support that strategy. When seasonal variations account for a significant part of the changes in consumer behavior, it is dangerous for a company to hold a dominant perception of time as a linear phenomenon. Secondly, and more broadly, the integration between action and reflection and the syntheses between the three pairs of approaches to time we suggest, point out that managers may not be dealing with as many paradoxes as the popular business press often assumes (e.g. Peters, 1987). Instead, they may be choosing between two appects of the same phenomenon. If this is indeed the case, then managers may be doing more harm than good by attempting to find a compromise or a 'winner' between two options that appear to be contradictory, when in fact they are not. Finally, because social science comes from the observation of reality, we call upon 
practitioners to enact the syntheses we propose here in order to allow for the advancement of organizational management and inquiry.

\section{CONCLUSION}

The twelve propositions articulated above constitute a contribution to a contingency view of time in organizations and an attempt to find a set of syntheses between apparently opposite perspectives on this phenomenon. In arriving at these propositions, we related different strategic orientations to different perspectives of the environment, arguing that when organizations have a dependent approach to their environment they prefer action to reflection. The opposite occurs if they have an independent approach to their environment. In this instance, they prefer reflection and planning to action and, finally, if they have an interdependent relationship with their environment, they will mostly rely on a synthesis between planning and action. These strategic orientations were then related to organizational approaches to the problems of scheduling, synchronization and time allocation. By doing this, we found that organizations that favor action over reflection tend to rely on event time to handle scheduling issues, to use entrainment to synchronize with their environment and mostly hold a linear view of time. Organizations that privilege reflection tend to rely on even time to handle scheduling issues, to impose its internal pacing to the environment and to hold a cyclic view of time. Organizations that attempt to find a synthesis between planning and action tend to solve scheduling issues via 'even event' time, synchronize via 'internal and external' pacing and hold a spiral (cyclic and linear) view of time. In the end, we were able to reach several syntheses between two apparently opposite views of time and, through the dominant strategic 
orientation, to provide a link between the approach to the environment and the choices regarding time-based decisions, thus contributing towards a contingency view of this phenomenon. Finally, our model has strengthened the argument for a dialectical view of organizations, where opposites are perceived as two elements of the same phenomena and paradoxes turned into syntheses. Ultimately, through the integration of sociological views of time and managerial approaches to strategy, we hope to have been able to persuade researchers that time is a topic worthy of inquiry, and practitioners that it is a viable instrument of management. 


\section{REFERENCES}

Aldrich, H. (1979) Organizations and environments. Englewood Cliffs, NJ: PrenticeHall.

Amabile, T. M. (1998) 'How to kill creativity'. Harvard Business Review, 76(4): 77-87.

Ancona, D., \& Chong, C.-L. (1996). Entrainment: Pace, cycle and rhythm in organizational behavior, in B.M. Staw \& L.L. Cummings (Eds.) Research in Organizational Behavior 18: 251-284. Greenwhich, CT: JAI Press.

Ansoff, H.I. (1991) 'Critique of Henry Mintzberg's 'The design school: Reconsidering the basic premises of strategic planning". Strategic Management Journal 12: 449-461.

Ansoff, H.I. (1994) 'Comment on Henry Mintzberg's 'Rethinking strategic planning'. Long Range Planning 27: 31-32.

Ansoff, H.I., Avner, J., Brandenburg, R.G., Portner, F.E., \& Radosevich, R. (1970) Does planning pay off? The effects of planning on success of acquisitions in American firms. Long Range Planning 3: 2-7.

Argyris, C. (1993) Knowledge for action. San Francisco: Jossey Bass.

Barnard, C. (1938) The functions of the executive. Cambridge, MA: Harvard University Printing Office.

Berger, P. \& Luckmann, T. (1967) The social construction of reality: A treatise in the sociology of knowledge. London: Penguin.

Bettis, R.A. \& Hitt, M.A. (1995) 'The new competitive landscape'. Strategic Management Journal 16: 7-19. 
Bluedorn, A.C. \& Denhardt, R.B. (1988) 'Time and organizations'. Journal of Management 14: 299-319.

Brews, P.J. \& Hunt, M.R. (1999) 'Learning to plan and planning to learn: Resolving the planning school/learning school debate'. Strategic Management Journal 20: 889913.

Brown, S.L., \& Eisenhardt, K.M. (1997) The art of continuous change: Linking complexity theory and time-paced evolution in relentlessly shifting organizations. Administrative Science Quarterly 42: 1-34.

Burrell, G. (1992) 'Back to the future: Time and organization', in M. Reed and M. Hughes (eds.) Rethinking organization: New directions in organizational theory and analysis, pp.165-183. London: Sage.

Campbell, J. (1949) The hero with a thousand faces. Princeton, NJ: Bollingen.

Cavendish, R. (1982) Women on the line. London: Routledge.

Chandler, A. (1962) Strategy and structure: Chapters in the industry of the American industrial enterprise. Cambridge, MA: MIT Press.

Ciborra, C.U. (1999) 'Notes on improvisation and time in organizations'. Accounting, Management \& Information Technology 9: 77-94.

Clark, P. (1978) 'Temporal innovations and time structuring in large organizations', in J. T. Fraser, N. Lawrence, \& D. Park (eds.) The study of time vol.3, pp.137-179. New York: Springer-Verlag.

Clark, P. 1985. A review of theories of time and structure for organizational sociology. In S.B. Bachrach \& S.M. Mitchel (Eds.), Research in the Sociology of Organizations, 4: 125-176. Greenwhich, CT: JAI Press. 
Clark, P. (1990) 'Chronological codes and organizational analysis', in J. Hassard \& D. Pym (eds.) The theory and philosophy of organizations: Critical issues and new perspectives, pp.137-163. London: Routledge.

Cooper, R.G. (1979) 'The dimensions of industrial new product success and failure'. Journal of Marketing 43(3): 93-103.

Craig, A. \& Hart, S. (1992) 'Where to now in new product development research'. European Journal of Marketing 26(11): 2-49.

Crossan, M.M. (1997) 'Improvise to innovate'. Ivey Business Quarterly 62: 37-42.

Crossan, M.M. (1998) 'Improvisation in action. Organization Science 9: 593-599.

Crossan, M.M., White, R.E., Lane, H., \& Klus, L. (1996) 'The improvising organization: Where planning meets opportunity'. Organizational Dynamics 24(4): 20-35.

Cunha, M.P., Cunha, J.V., \& Kamoche, K. (1999) 'Organizational improvisation: What, when, how and why'. International Journal of Management Reviews 1: 299-341.

D'Aveni, R.A. (1995) 'Coping with hipercompetition: Utilizing the new 7-S's framework'. Academy of Management Executive 9(3): 45-57.

Das, T.K. (1993) 'Time in management and organizational studies'. Time and Society 2: 267-274.

Deschamps, J.P., \& Nayak, P.R. (1995) Product juggernauts: How companies mobilize to generate a stream of market winners. Boston, MA: Harvard Business School Press.

Dill, W.R. (1962) 'The impact of environment on organizational development', in S. Mailick, \& E. H. Van Ness (eds.) Concepts and issues in administrative behavior. New York: Prentice-Hall.

Eisenhardt, K.M. (1989) 'Making fast strategic decisions in high-velocity environments'. 
Academy of Management Journal 32: 543-576.

Eisenhardt, K.M. (1997) 'Strategic decision making as improvisation', in V. Papadakis \& P. Barwise (eds.) Strategic Decisions, pp.51-257. Norwell, MA: Kluwer Academic Publishers.

Eisenhardt, K.M., \& Brown, S.L. (1998) 'Time pacing: Competing in markets that won't stand still'. Harvard Business Review 76: 59-69.

Eisenhardt, K.M. \& Tabrizi, B.N. (1995) 'Accelerating adaptive processes: Product innovation in the global computer industry'. Administrative Science Quarterly 40: 84-110.

Emery, F., \& Trist, E. (1965) 'The causal texture of organizational environments'. Human Relations 18: 21-32.

Ezzamel, M., \& Willmott, H. (1998) 'Accounting for teamwork: A critical study of group-based systems of organizational control'. Administrative Science Quarterly 43: $358-396$.

Filpcove, B., \& Filipovec, J. (1986) 'Society and concepts of time'. International Social Sciences Journal 107: 19-32.

Follett, M.P. (1940) 'Business as an integrative unit', in H.C. Metcalf, \& L. Urwick (eds.) Dynamic administration: The collected papers of Mary Parker Follett 71-94. New York: Harper \& Brothers.

Gearing, E. (1958) 'The structural poses of the 18th century Cherokee villages'. American Anthropologist 60: 1148-1157.

Gersick, C.J. (1991) 'Revolutionary change theories: A multilevel exploration of the punctuated equilibrium paradigm'. Academy of Management Review 32: 274-309. 
Gersick, C.J. \& Hackman, J.R. (1990) 'Habitual routines in task performing groups'. Organizational Behavior and Human Decision Processes 47: 65-97.

Greenleaf, R.K. (1979) Servant leadership: A journey into the nature of legitimate power and greatness. New York: Paulisi Press.

Greiner, L.E. (1972) 'Evolution and revolution as organizations grow'. Harvard Business Review 50(4): 37-46.

Hamel, G., \& Prahalad, C.K. (1994) Competing for the future: Breakthrough strategies for seizing control of your industry and controlling the markets of tomorrow. Boston: Harvard Business School Press.

Hammer, M. (1990) 'Reengineering work: Don't automate, obliterate'. Harvard Business Review 66(4): 98-109.

Hannan, M.T. \& Freeman, J. (1977) 'The population ecology of organizations'. American Journal of Sociology 82: 929-964.

Hassard, J. (1996) 'Images of time in work and organization', in S. R. Clegg, C. Hardy, \& W. R. Nord (eds.) Handbook of organization studies, pp.581-598. London: Sage.

Hatch, M.J. (1997) 'Jazzing up the theory of organizational improvisation'. Advances in Strategic Management 14: 181-191.

Hatch, M.J. (1999) 'Exploring the empty spaces of organizing: How improvisational jazz helps redescribe organizational structure'. Organization Studies 20: 75-100.

Hax, A.C., \& Majluf, N.S. (1983) 'The use of the growth-share matrix in strategic planning'. Interfaces 13: 17-33.

Hedberg, B.L.T., Nystrom, P.C., \& Starbuck, W.H. (1976) 'Camping on seesaws: Prescriptions for self-designing organizations'. Administrative Science Quarterly 
21: 41-65.

Hedley, B. (1976) 'A fundamental approach to strategy development'. Long Range Planning 9: 2-11.

Hutchins, E. (1991) ‘Organizing work by adaptation’. Organization Science 2: 14-39.

Iansiti, M. (1995) 'Shooting the rapids: Managing new product development in turbulent environments'. California Management Review 38(1): 1-22.

Johnson, B.M., \& Rice, R.E. (1984) 'Reinvention in the innovation process: The case of word processing, in R.E. Rice (ed.) The new media, pp.157-183. Beverly Hills: Sage.

Johnson, B.M., \& Rice, R.E. (1987) Managing organizational innovation: The evolution from word processing to office information systems. New York: Columbia University Press.

Katz, R. (1980) 'Time and work: Toward an integrative perspective', in B.M. Staw \& L.L. Cummings (eds.) Research in Organizational Behavior Vol.2, pp.81-127. Greenwhich, CT: JAI Press.

Kavanagh, D., \& Araujo, L. (1995) 'Chronigami: Folding and unfolding time'. Accounting, Management \& Information Technology 5: 103-121.

Lawrence, P.R., \& Lorsch, J.W. (1967) Organization and environment. Cambridge, MA: Harvard University Press.

Levitt, T. (1960) Marketing myopia. Harvard Business Review 38(4): 45-56.

Machin, D., \& Carrithers, M. (1996) 'From 'interpretative communities' to 'communities of improvisation". Media, Culture and Society 18: 343-352.

Maturana, H.R., \& Varela, F.J. (1980) Autopoiesis and cognition: The realization of the 
living. Dordecht, The Netherlands: D. Reidel.

McGrath, J.E., \& O'Connor, K.M. (1996) 'Temporal issues in work groups', in M. A. West (ed.), Handbook of work and group psychology, pp.25-52. London: John Wiley \& Sons.

McGrath, J.E. \& Rotchford, N.L. (1983) 'Time and behavior in organizations', in B.M. staw \& L.L. Cummings (eds.) Research in Organizational Behavior Vol.5, pp.57101. Greenwhich, CT: JAI Press.

Miller, D. (1993) 'The architecture of simplicity'. Academy of Management Review, 18: $116-138$

Miller, D., \& Cheng, M.-J. (1994) 'Sources and consequences of competitive inertia: A study of the U.S. airline industry'. Administrative Science Quarterly 39: 1-23.

Miner, A., Moorman, C., \& Bassoff, P. (1997) 'Organizational improvisation in new product development'. Report No. 97-110. Cambridge, MA: Marketing Science Institute.

Mintzberg, H. (1975) 'The manager's job: Folklore and fact'. Harvard Business Review 53: 49-61.

Mintzberg, H. (1990) 'The design school: Reconsidering the basic premises of strategic management'. Strategic Management Journal 11: 171-195.

Mintzberg, H. (1991) 'Learning 1, Planning 0: Reply to Igor Ansoff'. Strategic Management Journal 12: 463-466.

Mintzberg, H. (1994) The rise and fall of strategic planning. New York: Free Press.

Mintzberg, H. (1995) 'The structuring of organizations', in H. Mintzberg, J.B. Quinn, \& S. Ghoshal (eds.) The strategy process: European edition, pp.350-371. 
Hertfordshire: Prentice-Hall.

Moorman, C., \& Miner, A. (1998) 'The convergence between planning and execution: Improvisation in new product development'. Journal of Marketing 62: 1-20.

Moorman, C., \& Miner, A. (1998) 'Organizational improvisation and organizational memory'. Academy of Management Review 23: 698-723.

Orlikowski, W.J. (1996). 'Improvising organizational transformation over time: A situated change perspective'. Information Systems Research 7: 63-92.

Orlikowski, W.J., \& Hofman, J.D. (1997) 'An improvisational model for change management: The case of groupware technologies'. Sloan Management Review 38(2): 11-21.

Orlikowski, W.J. \& Yates, J. (1998) It's about time: An enacted view of time in organizations, paper presented at the Academy of Management meeting (August), San Diego.

Ouchi, W.G. (1980) 'Markets, bureaucracies and clans'. Administrative Science Quarterly 25: 129-141.

Pascale, R.T. (1995) 'The Honda effect', in H. Mintzberg, J. B. Quinn, \& S. Ghoshal (eds.) The strategy process: European edition. Hetfordshire: Prentice-Hall.

Pentland, B.T., \& Reuter, H.H. (1994) 'Organizational routines as grammars of action'. Administrative Science Quarterly 39: 484-510.

Peters, T.J. (1987) Thriving on chaos: Handbook for a management revolution. New York: Alfred A. Knopf.

Peters, T.J. (1992) Liberation management: The necessary disorganization for the nanosecond nineties. New York: Alfred A. Knopf. 
Porter, M.E. (1982) Competitive advantage: Creating and sustaining superior performance. New York: Free Press.

Powell, W.W. (1990) 'Neither market nor hierarchy: Network forms of organization, in L.L. Cummings \& B.M. Staw (eds.), Research in Organizational Behavior, pp.295336. Greenwich, CT: JAI Press.

Prahalad, C.K., \& Hamel, G. (1990) 'The core competence of the corporation'. Harvard Business Review 68(3): 79-91.

Roberts, C. (1994) 'Intrapersonal mastery', in P.M. Senge, C. Roberts, R. Ross, B. J. Smith, \& A. Kleiner (Eds.), The fifth discipline fieldbook: Strategies and tools for building a learning organization. London: Nicholas Brealey.

Smircich, L., \& Stubbart, C. (1985) 'Strategic management in an enacted world'. Academy of Management Review 26: 724-736.

Stacey, R.E. (1991) The chaos frontier: Creative and strategic control for business. Oxford: Butterworth-Heinemann.

Stacey, R.E. (1996) Complexity and creativity in organizations. San Francisco: BerrettKoehler.

Stalk, G., \& Hout, T.M. (1990) Competing against time: How time based competition is reshaping global markets. New York: Free Press.

Thayer, L. (1988) 'Leadership/communication: A critical review and a modest proposal', in G. M. Goldhaber, \& G.A. Barnett (eds.) Handbook of organizational communication, pp.231-263. Norwood, NJ: Ablex.

Tyre, M. J., Perlow, L., Staudenmayer, N., \& Wasson, C. (1996) Time as a trigger for organizational change, paper presented at the Academy of Management meeting 
(August), Cincinnati.

Weick, K.E. (1979) The social psychology of organizing (2nd. ed.). New York: McGrawHill.

Weick, K.E. (1993) Organizational redesign as improvisation, in G. P. Huber \& W. H. Glick (eds.) Organizational change and redesign, pp.346-379. New York: Oxford University Press.

Weick, K.E. (1995) Sensemaking in organizations. Thousand Oaks, CA: Sage.

Weick, K.E. (1996) 'Drop your tools: An allegory for organizational studies'. Administrative Science Quarterly 41: 301-313.

Weick, K.E. (1999) 'The aesthetic of imperfection in orchestras and organizations'. Comportamento Organizacional e Gestão 5: 5-22.

Yates, J., \& Orlikowski, W.J. (1999) Knee-jerk, anti-LOOPism and other e-mail phenomena: Oral, written, and electronic patterns in computer-mediated communication. Technical report \#150. Cambridge, MA: Center for Coordination Science. 